\title{
Evidence of exposure of laughing doves (Spilopelia senegalensis) to West Nile and Usutu viruses in southern Tunisian oases
}

\author{
T. AYADI ${ }^{1}$, A. HAMMOUDA ${ }^{1}$, A. POUX ${ }^{2}$, T. BOULINIER $^{3}$, S. LECOLLINET $^{2}$ \\ AND S. SELMI ${ }^{1 *}$ \\ ${ }^{1}$ Unité de Recherche 'Ecologie de la Faune Terrestre' (UR17ES44), Faculté des Sciences, Université de Gabès, \\ Gabès, Tunisia \\ ${ }^{2}$ UPE, ANSES, Laboratoire de Santé Animale de Maisons-Alfort, UMR1161 Virologie, INRA, ANSES, ENVA, \\ Maisons-Alfort, France \\ ${ }^{3}$ Centre d'Ecologie Fonctionnelle et Evolutive, CNRS-Université de Montpellier UMR 5175, France
}

Received 28 March 2017; Final revision 3 July 2017; Accepted 17 July 2017; first published online 14 August 2017

\section{SUMMARY}

It has previously been suggested that southern Tunisian oases may be suitable areas for the circulation of flaviviruses. In order to anticipate and prevent possible epidemiological spread of flaviviruses in humans and domestic animals, the ecology of their transmission in the oasis system needs to be better understood. Thus, the aim of this study was to assess the seroprevalence of anti-flavivirus antibodies in the laughing dove (Spilopelia senegalensis), an abundant resident bird in Tunisian oases. Anti-flavivirus antibodies were detected in 17\% of sampled doves. Ten per cent of the total tested doves were West Nile virus (WNV) seropositive and $4 \%$ were Usutu virus (USUV) seropositive, which provides the first evidence of USUV circulation in Tunisian birds. We also found that the occurrence probability of anti-flavivirus antibodies in dove plasma increased with decreasing distance to coast, suggesting that doves inhabiting coastal oases were more exposed to flaviviruses compared with those inhabiting inland oases. We also found significantly higher antibody occurrence probability in adult doves compared with young doves, which underlines the effect of exposure time. Overall, our results suggest that the laughing dove may be used for WNV and USUV surveillance in southern Tunisia. They also stress the need for investigations combining data on birds and mosquitoes to better understand the ecological factors governing the circulation of flaviviruses in this area.

Key words: Laughing dove, oasis, Tunisia, Usutu virus, West Nile virus.

\section{INTRODUCTION}

During the last decade, West Nile virus (WNV) and Usutu virus (USUV), both belonging to the Japanese encephalitis virus group (family Flaviviridae), have emerged and the area over which their circulation

\footnotetext{
* Author for corresponding: Dr Slaheddine Selmi, Faculté des Sciences de Gabès, Zrig 6072, Gabès, Tunisia.

(Email: slah_selmi@yahoo.fr)
}

was detected has extended in the Mediterranean basin [1-3]. WNV was first isolated in Uganda in 1937 before drastically spreading across the world, causing several outbreaks and sporadic cases in novel locations [2-5]. Although most human infections with WNV are clinically silent, some WNVinfected patients develop neuroinvasive disease that can manifest as meningitis, encephalitis and/or myelitis. In Tunisia, WNV has been associated with three major West Nile outbreaks in humans: in 1997 
(173 cases, with eight deaths), in 2003 (21 cases and three deaths) and in 2012 (86 cases and 12 deaths) [6-11]. USUV was discovered in South Africa in 1959, and since then has been detected in several other African and European countries [1]. However, USUV is substantially less virulent for human health in comparison with WNV. Until now, few cases of neuroinvasive disease related to USUV have been reported [12, 13]. In Tunisia, USUV was detected recently for the first time, in the governorate of Kébili [14].

Both WNV and USUV have similar transmission cycles, with birds acting as the main amplifying hosts and mosquitoes, mainly from the Culex genus, as vectors [1, 2]. Under suitable ecological conditions, WNV spillover to humans and other mammals can occur [15]. Indeed, a panel of biotic and abiotic factors can govern the intensity of WNV transmission cycle, with climate, availability of water bodies (such as lakes, ponds, streams, reservoirs and canals), land use and host community composition among the most important $[10,16,17]$. These factors can directly affect the abundance of reservoir hosts and vectors, and consequently, WNV and USUV transmission [17].

In southern Tunisia, the landscape is marked by the presence of numerous isolated oases, which contrast with the surrounding dry and bare desert environment [18]. These wet and densely vegetated areas host abundant bird populations [19-21] and provide suitable habitat conditions for mosquitoes [10]. Oases are also characterized by high human presence as they are agro-ecosystems directly dependent on human activities (irrigation, plowing, weeding and maintenance). Typically, human settlements are organized in small agglomerations surrounded very closely by irrigated fields [18]. Many residents are farmers and spend a lot of time in the fields, which exposes them to mosquito bites. In addition, mosquitoes are frequently observed inside houses. An oasis is thus a place where humans, mosquitoes and birds concentrate in a relatively small space. Knowing that the transmission of flaviviruses is strongly associated with the presence of wetlands and the abundance of birds and mosquitoes [22], southern Tunisian oases seem to offer suitable conditions for flavivirus circulation, thus underlining possible serious risks for human health and livestock populations. In fact, WNV outbreaks have been described in some oases in southern Tunisia, namely Gabès in 2003 and Tozeur, Kébili and Gabès in 2012 [11]. To anticipate and prevent possible spread of flaviviruses in humans and domestic animals, the ecology of their transmission in the oasis system needs to be better understood. This can be done using serological tools that allow assessment of whether a bird population has been exposed to flaviviruses through the detection of specific antibodies [23].

The detection of antibodies in a bird means that the bird has been infected in the course of its lifetime, without knowing exactly when or under what conditions. Thus, by using the antibody detection approach, we can know if a bird has been exposed to viruses, but not to study the circumstances of virus transmission. It is also possible to investigate hypotheses about factors that may influence the exposure of birds to viruses. These factors may include bird-related parameters, as well as habitat features. For instance, antibody occurrence probability could be expected to increase with bird age because adults are more likely to have been exposed to viruses than young birds. Indeed, as the host gets older, the risk of having been bitten by a mosquito carrying the virus increases. In addition, all habitat parameters that increase the abundance of mosquitoes and promote their encounters with birds could also be hypothesized to increase the exposure of birds to viruses.

With regard to southern Tunisian oases, we expected vegetation structure to affect bird exposure to viruses, through its possible effects on microclimate conditions and water availability, and hence the abundance of mosquitoes and birds. In fact, two types of oases exist in this area: traditional oases characterized by a mixture of cultivated and spontaneous plants organized into three main layers (palm trees, fruit trees and herbaceous plants) and modern oases where the vegetation is composed of regular rows of palm trees with the quasi-absence of other crops [21]. Traditional oases are thus expected to offer more suitable habitat conditions for virus circulation than the modern and less vegetated ones. Furthermore, Oasis position relative to the Mediterranean coast is also expected to affect bird exposure to flaviviruses. Indeed, inland areas are more influenced by Sahara and have drier climates than coastal areas which are subjected to maritime influence.

To our knowledge, the exposure of birds to WNV in southern Tunisia has only been addressed in one recent work on sparrows inhabiting two oases [24], while the exposure of wild birds to USUV has never been reported. One further species that may be used for investigating bird exposure to flaviviruses in southern Tunisian oases is the laughing dove (Spilopelia senegalensis), as it is one of the most abundant and 
widespread bird species in this area [19]. Furthermore, this resident bird shows anthropophilic behaviour and occurs frequently in the close surroundings of human settlements, as it often feeds in stables, cowsheds and barns, sharing water troughs with livestock and poultry.

The competence of Columbiforms as natural reservoirs for flaviviruses is controversial. Columbiforms are most often regarded as low competent hosts for flaviviruses $[25,26]$, but some other studies suggest that pigeons, which are widely prevalent in highly populated as well as rural areas, could be competent reservoirs [27, 28]. Laughing doves that were experimentally infected with WNV did not develop any specific illness [26], and the low viraemia observed in many instances in Columbiforms make it unlikely, although not impossible, that laughing doves are reservoirs of WNV. For all these reasons, we believe that the laughing dove may be a candidate for exploring bird exposure to WNV and USUV in southern Tunisian oases and to act as a potential sentinel for the presence of flaviviruses [29].

In this study, we assessed the seroprevalence of WNV and USUV antibodies in laughing doves inhabiting four different oases in Southern Tunisia. Our oasis sample included traditional and modern oases located at different distances from the coast. We conducted generalized linear mixed models (GLMMs) to model the probability of antibody occurrence as a function of dove age and oasis features. For the reasons exposed above, we predicted that antibody occurrence probability is higher in adult doves compared with young doves, and in traditional oases compared with modern oases. A negative relationship between antibody occurrence probability and oasis distance to coast was also expected.

\section{METHODS}

\section{Study species}

The laughing dove is a medium Columbiform native to most of sub-Saharan Africa, Middle-East and Indian subcontinent [30]. In North Africa, this dove species inhabits a variety of natural and man-made habitats, such as oases, farmlands and areas close to human settlements [19, 31]. It is nowadays one of the most widespread and abundant birds in southern Tunisian oases [19, 31], where it mainly nests on olive and pomegranate trees with a high reproductive success [32]. This dove species is typically resident and sedentary, but it shows a high dispersal ability [30]. Originating from sub-Saharan Africa, it succeeded in colonizing the entire North Africa in less than a century, but this expansion appears to be the result of erratic movements of individuals rather than population migrations [19, 31].

\section{Study sites}

Data were collected in four oases representing each of the four main oasis regions in southern Tunisia: Degache oasis $\left(33^{\circ} 58^{\prime} 21 \cdot 45^{\prime} \mathrm{N}-8^{\circ} 12^{\prime} 31 \cdot 74^{\prime} \mathrm{E}\right)$ in the Djerid region, Oum-Errous oasis $\left(33^{\circ} 32^{\prime} 29^{\prime} \mathrm{N}-8^{\circ} 55^{\prime}\right.$ $\left.42^{\prime} \mathrm{E}\right)$ in the Nefzaoua region, Gafsa oasis $\left(34^{\circ} 24^{\prime} 27^{\prime}\right.$ $\left.\mathrm{N}-8^{\circ} 46^{\prime} 14^{\prime} \mathrm{E}\right)$ in Gafsa region and Kettana oasis ( $33^{\circ}$ $\left.46^{\prime} 17^{\prime} \mathrm{N}-10^{\circ} 11^{\prime} 25^{\prime} \mathrm{E}\right)$ in the coastal Gabès region (Fig. 1). Kettana and Gafsa are traditional oases characterized by a mixture of cultivated and spontaneous plants organized into three main layers, namely palm trees, fruit trees (notably olive, pomegranate, apricot and fig trees) and herbaceous plants. However, Degache and Oum-Errous are modern oases characterized by simpler vegetation dominated by palm trees.

\section{Sample collection and laboratory analyses}

In Kettana, Oum-Errous and Gafsa oases, laughing dove sampling took place in June and September 2015. However, in Degache oasis, doves were only sampled in June 2015. Laughing doves were captured using mist nets placed around highly frequented feeding sites (cowsheds and grain storage garages). Upon capture, we determined dove age (adult vs. young) based on plumage colour: the presence of a complete spotted black band across the lower fore-neck indicated an adult [30]. A $0.5 \mathrm{ml}$ blood sample was taken from the brachial vein using a sterile heparinized syringe. The blood sample was then transferred into a heparinized $2 \mathrm{ml}$ tube and maintained in a cooler $\left(4^{\circ} \mathrm{C}\right)$ while in the field. Before releasing, the sampled doves were ringed to avoid resampling.

Blood samples were brought to the laboratory on the day of collection, where they were centrifuged $(10 \mathrm{~min}$ at $5000 \mathrm{~g})$. The plasma samples were then stored at $-20^{\circ} \mathrm{C}$ until immunological analyses could be performed. Screening of sera for flavivirus antibodies was conducted using an ELISA kit designed to detect antibodies against the structural premembrane (prM) and envelope (E) proteins of WNV (ID Screen ${ }^{\circledR}$ West Nile Competition, IDvet, France). Because WNV E protein shares conserved epitopes 


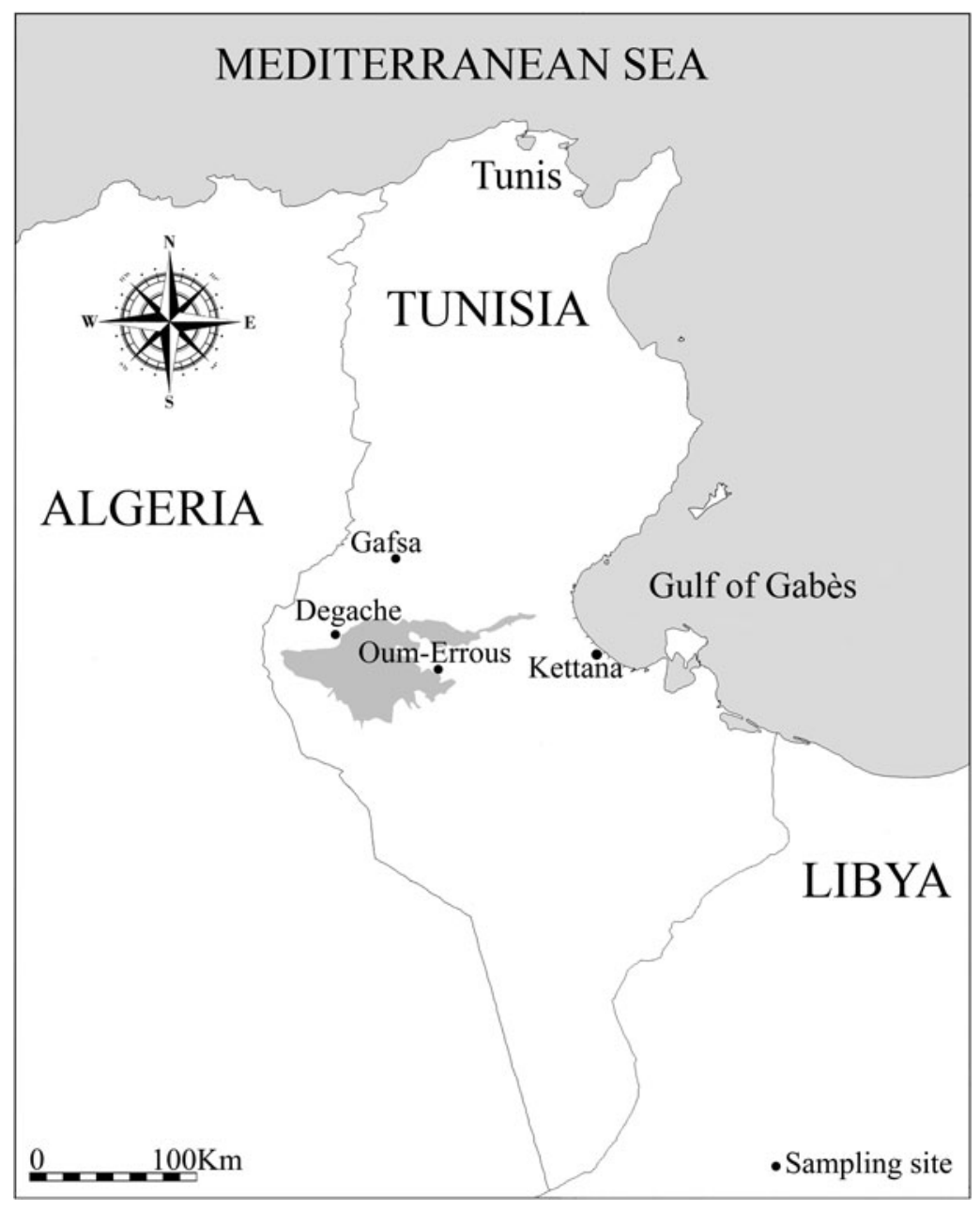

Fig. 1. Map of southern Tunisia showing the location of sampled oases.

with other flaviviruses, this ELISA tool can be conveniently used as a surrogate test to detect antibodies to many flaviviruses, particularly those belonging to the Japanese encephalitis serocomplex [33]. ELISApositive samples were further investigated through virus-specific microneutralization tests (MNTs) against flaviviruses reported in the area where the sera were collected [33-35].

Heat-inactivated sera, serially diluted (1:5 to $1: 320)$ in Dulbecco's modified Eagle's medium (DMEM) were mixed with an equal volume $(50 \mu \mathrm{l})$ of DMEM containing 100 tissue culture infectious dose 50 of WNV strain IS-98-ST1 (provided by the National Reference Centre for Arboviruses in France at the Institut Pasteur, Paris) or USUV strain It2012 (206795-3, generous gift from IZSLER, Brescia). Each serum was tested in duplicate. Cell and virus controls, as well as virus back titration controls, were included in every MNT assay. After incubation of the plates at $37^{\circ} \mathrm{C}$ for $1.5 \mathrm{~h}, 2 \times 10^{4}$ Vero cells in
$100 \mu \mathrm{l}$ of DMEM were added to all the wells. Plates were incubated at $37^{\circ} \mathrm{C}$ for 3 days, and then cytopathogenic effects were observed under a light microscope. A serum was considered negative if infection occurred regardless of serum concentration. It was considered positive if cells were protected at the 1:10 serum dilution; its titre was calculated as the inverse of the latest dilution at which cells were protected [35]. Owing to cross-neutralization between flaviviruses, especially within the same serocomplex, virus neutralisation test (VNT) end point titres require comparison. The flavivirus can then be identified as the virus with the highest titre, i.e. the one that shows a titre at least four times higher than that of the other $[35,36]$.

\section{Data analyses}

The relevance of dove age and oasis features as predictors of the occurrence probability of anti-flavivirus antibodies was investigated by means of a GLMM, with a logit 
link-function and binary distribution, using the GLIMMIX procedure in SAS software [37]. In this model, oasis type (two classes: traditional vs. modern), distance to coast (continuous variable) and dove age (two classes: young vs. adult) were considered as fixed effects. Sampling period (two classes: June vs. September) was also considered as a fixed effect, while oasis identity was considered as a random factor. A similar model was also used for modelling the occurrence probability of anti-WNV antibodies using the data obtained by the virus MNT. However, the occurrence probability of anti-USUV antibodies was not investigated due to low occurrence (please see results below).

\section{RESULTS}

A total of 226 laughing doves were sampled in the four studied oases (Table 1). Using ELISA, anti-flavivirus antibodies (including anti-WNV and anti-USUV antibodies) were detected in 38 samples, corresponding to an overall prevalence of $17 \%(95 \%$ CI $12-22 \%$ ). Among these samples, 22 were WNV seropositive and nine were USUV seropositive, as revealed by the virus MNT, corresponding, respectively, to $10 \%(95 \%$ CI $6-14 \%)$ and $4 \%(95 \%$ CI $1-7 \%$ ) of sampled doves.

Results of the GLMM showed that neither sampling period nor oasis type provided a significant predictor of the occurrence probability of anti-flavivirus antibodies in dove plasma. However, there was a significant effect of dove age (Table 2). The occurrence probability of anti-flavivirus antibodies was four times higher in adult doves compared with young ones (Fig. 2). There was also a significant negative relationship between distance to coast and antibody occurrence probability (Table 2, Fig. 3).

Our results also showed that none of the investigated variables significantly affected the occurrence probability of anti-WNV antibodies (Table 2). There were trends towards increased antibody occurrence probability in adult doves (estimated least square mean \pm S.E. $=0 \cdot 113 \pm 0 \cdot 030)$ compared with young ones (estimated least square mean \pm s.E. $=0.055 \pm 0.024$ ) and towards decreased antibody occurrence probability with increasing distance to coast $(\beta \pm$ S.E. $=-0 \cdot 010 \pm$ $0 \cdot 006$ ), but these trends were not significant (Table 2).

\section{DISCUSSION}

In this study, we investigated the seroprevalence of anti-flavivirus antibodies in the laughing dove
(S. senegalensis), a bird species that has the potential to act as a sentinel for the presence of flaviviruses in the oases of southern Tunisia. Our results showed that $10 \%$ of sampled doves were WNV seropositive and $4 \%$ were USUV seropositive. They also showed that dove exposure to flaviviruses increased with dove age and decreased with oasis distance to coast.

Our results are consistent with previous studies, which underlined an established WNV transmission cycle in Tunisia $[14,15,24,34]$. They are in accordance with frequent observations of high WNV infection rates in doves and pigeons, generally associated with WNV outbreaks [38-40]. However, the overall anti-WNV seroprevalence rate we report here is higher than that found in sparrows in the same area $(1 \%)$ [24]. Several hypotheses could explain this difference. First, it could be a consequence of a recent virus activity in the studied oases, which is supported by the fact that some young doves $(<1$ year old) were WNVpositive. It may also be due to higher exposure risks of doves to viruses in comparison with sparrows, which is consistent with the general tendency of positive association between seroprevalence rate and bird body size [41]. Because of their larger bodies, doves may be more likely to be attractive to mosquitoes, and hence more exposed to viruses, than sparrows. Indeed, larger birds produce higher levels of $\mathrm{CO}_{2}$, and may be more attractive to vectors in comparison with small ones [41]. Other ecological differences between doves and sparrows may also affect their exposure to mosquitoes. For instance, laughing doves are exclusively groundfeeders and nest on small fruit trees at low heights [19, 32], while sparrows spend less time close to the ground as they frequently feed on fruit trees and use high palm and eucalypt trees, as well as human settlements for nesting [32]. Thus, doves may remain in contact with some mosquito species more frequently and for longer time than sparrows, knowing that Culex pipiens (L.), which has been reported as the main vector of WNV in Tunisia [15], prefers ground-level habitats [42]. Relationships between host availability, host preference and mosquito habitat use are nevertheless complex and further studies on the systematic of mosquitoes in the oasis habitat and their ecology (especially habitat use and feeding behaviour) are needed to better understand birds' exposure to viruses. Such studies could use sets of baited traps in habitats with different characteristics [43].

Our results showed a significant effect of dove age on the prevalence of total anti-flavivirus antibodies. The occurrence probability of anti-flavivirus 
Table 1. Antibody prevalence to flaviviruses (including WNV and USUV) in laughing doves (Spilopelia senegalensis) in Tunisian oases, using ELISA and neutralization assays

\begin{tabular}{lllll}
\hline \hline Site & Number of doves tested & Positive ELISA (general flavivirus) & WNV-positive (VNT) & USUV-positive (VNT) \\
\hline Gafsa & 53 & $7(13 \%)$ & $3(6 \%)$ & $4(8 \%)$ \\
Kettana & 102 & $23(23 \%)$ & $15(15 \%)$ & $3(3 \%)$ \\
Oum-Errous & 45 & $7(16 \%)$ & $3(7 \%)$ & $2(4 \%)$ \\
Degache & 26 & $1(4 \%)$ & $1(4 \%)$ & $0(0 \%)$ \\
Total & 226 & $38(17 \%)$ & $22(10 \%)$ & $9(4 \%)$ \\
\hline \hline
\end{tabular}

Table 2. Results of GLMMs of the occurrence probability of anti-flavivirus and anti-WNV antibodies as functions of sampling period ( two classes: September $=0$ vs. June $=1)$, oasis type $($ two classes: traditional $=0$ vs. modern $=1)$, oasis distance to coast (continuous variable) and dove age (young $=0$ vs. adult $=1)$ as fixed effects and oasis identity as a random factor

\begin{tabular}{lllll}
\hline \hline Effect & Estimate \pm s.E. & DF & $T$ & $P$ \\
\hline Anti-flavivirus antibodies & & & & \\
$\quad$ Sampling period & $0 \cdot 125 \pm 0 \cdot 437$ & 221 & $0 \cdot 28$ & $0 \cdot 7761$ \\
Oasis type & $0 \cdot 018 \pm 0 \cdot 593$ & 221 & $0 \cdot 03$ & $0 \cdot 9755$ \\
Distance to coast & $-0.010 \pm 0.004$ & 221 & $-2 \cdot 32$ & $0 \cdot 0214$ \\
$\quad$ Dove age & $1 \cdot 483 \pm 0 \cdot 482$ & 221 & $3 \cdot 08$ & $0 \cdot 0023$ \\
Anti-WNV antibodies: & & & & $0 \cdot 5436$ \\
$\quad$ Sampling period & $-0 \cdot 330 \pm 0.542$ & 221 & $-0 \cdot 61$ & $0 \cdot 7239$ \\
Oasis type & $0 \cdot 284 \pm 0 \cdot 804$ & 221 & $0 \cdot 35$ & $0 \cdot 1008$ \\
Distance to coast & $-0.010 \pm 0.006$ & 221 & $-1 \cdot 65$ & $0 \cdot 1314$ \\
Dove age & $0 \cdot 787 \pm 0 \cdot 520$ & 221 & $1 \cdot 51$ & \\
\hline \hline
\end{tabular}

antibodies was four times higher in adult doves compared with young ones, which is consistent with other investigations of mosquito-borne flaviviruses $[10,38]$. As the host gets older, the exposure time to mosquito bites, and hence virus infection, increases. However, we did not find a significant difference between the two age classes regarding anti-WNV prevalence, although there was a trend towards increased anti-WNV occurrence probability in adults compared with young doves. This may be due to a possible misclassification of some young doves as adults, thus increasing erroneously the number of negative individuals among adults. Because dove age determination was based on plumage, it could be that some early fledged young doves have completely moulted their plumage during summer and were misleadingly classified as adults in September samples. This possible misclassification of young doves as adults may have also induced an underestimation of the effects of dove age on the occurrence probability of total anti-flavivirus antibodies. An alternative explanation could be a recent circulation of WNV in the studied area during the sampling period, thus affecting doves independently of their ages. Knowing that during early summer mosquitoes reach their peak abundance [44], and that birds and mosquitoes can be forced into greater contact by congregating around water points thereby increasing virus transmission $[45,46]$, this hypothesis seems plausible. However, under this hypothesis, an increase in WNV antibodies in September samples compared with June ones would be expected, which is not supported by our data.

One of the key findings of our work is that laughing dove exposure to flaviviruses was more related to oasis geographic location rather than vegetation structure. Indeed, contrary to our expectation, the occurrence probability of anti-flavivirus antibodies in laughing doves did not differ between traditional and modern oases. In both systems, local habitat parameters appear to be sufficiently similar that they provide comparable conditions for flavivirus circulation. Although there are differences in tree density and stratification, the water surfaces required for mosquito larval development, which are also used by doves for drinking, are available continuously in both 


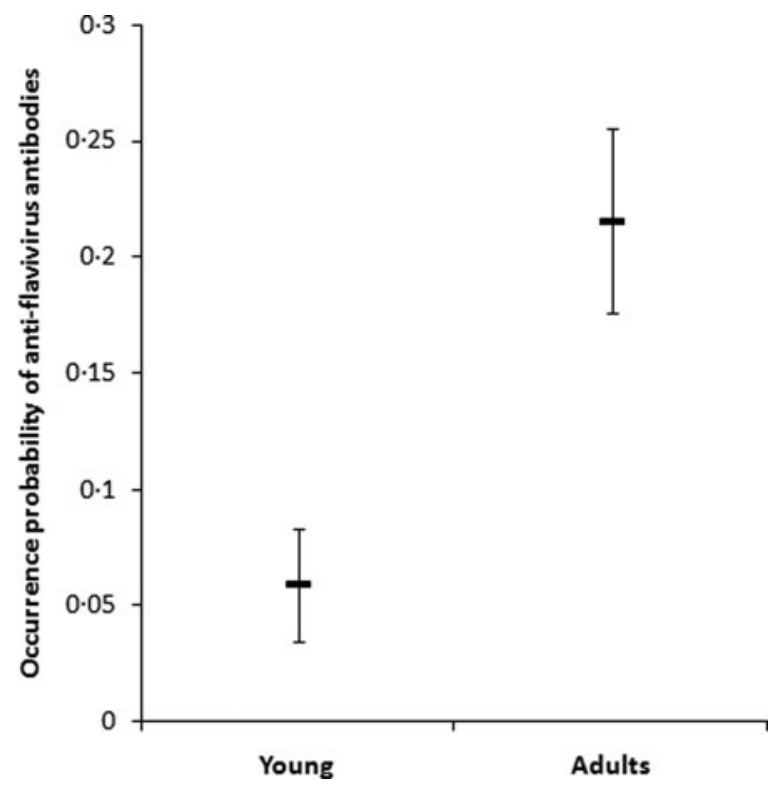

Fig. 2. Estimated least square means ( \pm s.e.) of the occurrence probability of anti-flavivirus antibodies in young and adult laughing doves from a GLMM accounting for oasis type, distance to coast and sampling period as fixed effects, and oasis identity as a random factor.

types of oases. These are mainly open water in irrigation systems, drains, surface wells and water tanks. However, our results suggest that it is rather the overall climatic differences between coastal areas (subjected to maritime influence) and those of the interior (influenced by Sahara) that seem to play the most important role in shaping the spatial variation in dove exposure to flaviviruses. Indeed, we found that doves inhabiting littoral oases were more exposed to flaviviruses compared with those in inland oases. This finding is consistent with our expectation and also with the findings of previous studies on the spatial distribution of flaviviruses in the Mediterranean basin and Tunisia $[10,47]$. In southern Tunisia, the inland areas experience higher temperatures and evaporation rates in comparison with the coast. This may limit sustained mosquito populations in inland oases, thus resulting in lower circulation of flaviviruses compared with coastal ones. However, further studies taking into account the impact of climatic conditions on the abundance of mosquitoes in these areas are needed to specifically investigate the spatial variation in the exposure of laughing doves to flaviviruses.

Our results provide the first evidence of USUV circulation in Tunisian avifauna. This finding is consistent with the results of a previous investigation

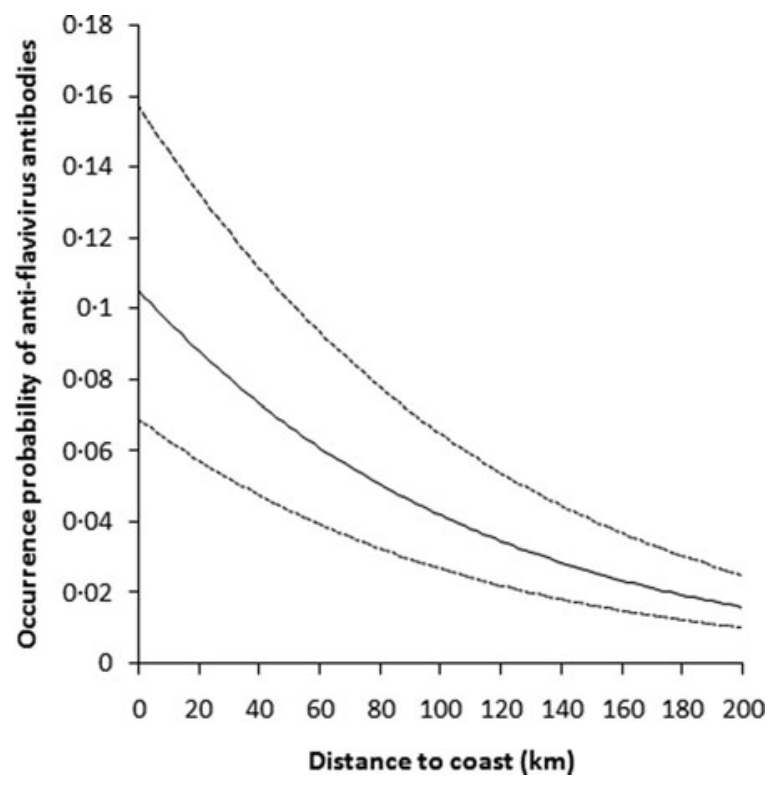

Fig. 3. Plot of the relationship between the occurrence probability of anti-flavivirus antibodies and oasis distance to coast, as estimated from a GLMM accounting for dove age, oasis type and sampling period as fixed effects, and oasis identity as a random factor. Dashed lines represent the $95 \%$ confidence interval limits.

reporting WNV and USUV co-circulation in horses in the region of Kébili [14]. In a recent review, it has been reported that WNV and USUV co-circulate in 10 countries in Europe and infect 34 common bird species that belong to 11 orders, including Columbiformes [3]. However, in the studied laughing dove population, anti-USUV antibodies were at lower prevalence than anti-WNV antibodies. Moreover, anti-USUV seropositivity was only recorded in adult doves sampled in June (early summer). The fact that antibodies were detected in adult doves but not in young ones would suggest a previous USUV activity that dates back at least a year before our investigation, especially as flavivirus antibody levels are known to persist for a long time in birds [48]. It could alternatively be due to differential USUV-induced mortality between adults and young doves. USUV is known to be more virulent to birds than WNV and to cause higher mortality rates $[1,3]$. Therefore, young doves that have not yet developed effective immunity are expected to have a higher risk of dying as a result of USUV infections than adults.

It is noteworthy that some flavivirus-positive samples were not characterized as either WNV or USUV-positive. Two main hypotheses could be suggested to explain this finding. First, it could be that 
the infected birds have developed a weak neutralizing response, which is often observed in ELISA low positives (with values close to the test threshold). Alternatively, this result may indicate the circulation of other flaviviruses in the study area. The latter hypothesis may be verified by the molecular screening of arthropods living in the studied area.

In conclusion, this work provides evidence of WNV and USUV circulation in the birds inhabiting southern Tunisian oases. It also suggests that the laughing dove, an abundant and widespread bird species in southern Tunisia, may be used for WNV and USUV surveillance in this area. Furthermore, our results demonstrate the effects of some ecological factors governing the circulation of flaviviruses in this area. However, we believe that further investigations combining data on birds and mosquitoes from a larger sample of oases are needed to describe the ecology and transmission cycles of WNV and USUV in southern Tunisia.

\section{ACKNOWLEDGEMENTS}

The authors wish to thank J. Vandekerkhove, S. Lowenski, C. Beck, C. Loiseau, M. Ayadi, H. Bellil and $\mathrm{H}$. Belwafi who helped in laboratory and field work, as well as P. Desprès (Institut Pasteur) and D. Lelli (IZSLER) for the provision of WNV and USUV field strains respectively. The authors also thank Dr Andrew Breed and four anonymous reviewers on their valuable comments on an earlier version of the manuscript. ELISAs were conducted at PACE Labex CEMEB platform. This work was conducted as a part of the OISAU-FCAIMED project financed by the DGRST-CNRS collaboration program (grant number 14/R0901). Support was also provided by OSU OREME and CNRS INEE. Authorizations for bird sampling were obtained from the Forest Service of the Tunisian Ministry of Agriculture (permit number 1035/ 04-05-2015).

\section{DECLARATION OF INTEREST}

None.

\section{REFERENCES}

1. Ashraf U, et al. Usutu virus: an emerging flavivirus in Europe. Viruses 2015; 7: 219-238.

2. Chancey C, et al. The global ecology and epidemiology of West Nile virus. BioMed Research International 2015; 2015: 376230, doi:10.1155/2015/376230.
3. Nikolay B. A review of West Nile and Usutu virus co-circulation in Europe: how much do transmission cycles overlap? Transactions of the Royal Society of Tropical Medicine and Hygiene 2015; 109: 609-618.

4. Murgue B, et al. West Nile in the Mediterranean Basin: 1950-2000. Annals of the New York Academy of Sciences 2001; 951: 117-126.

5. Randolph SE, Rogers DJ. The arrival, establishment and spread of exotic diseases: patterns and predictions. Nature Reviews Microbiology 2010; 8: 361-371.

6. Triki H, et al. Méningo-encéphalite à arbovirus West Nile en Tunisie. Médecine Tropicale 2001; 61: 487-490.

7. Feki I, et al. Epidemic West Nile virus encephalitis in Tunisia. Neuroepidemiology 2005; 24: 1-7.

8. Hachfi $\mathbf{W}$, et al. Une deuxième épidémie de méningoencéphalite à virus West Nile en Tunisie. Médecine et Maladies Infectieuses 2010; 40: 456-461.

9. Riabi S, et al. Prevalence of IgG antibodies against West Nile virus in blood donors during the 2003 outbreak in Tunisia. Transactions of the Royal Society of Tropical Medicine and Hygiene 2010; 104: 507-509.

10. Ben Hassine T, et al. Identification of suitable areas for West Nile virus circulation in Tunisia. Transboundary and Emerging Diseases 2017; 64: 449-458.

11. Benjelloun A, et al. West Nile Disease Epidemiology in North-West Africa: bibliographical review. Transboundary and Emerging Diseases 2016; 63: e153-e159. doi:10.1111/ tbed.12341.

12. Vázquez A, et al. Usutu virus-potential risk of human disease in Europe. Eurosurveillance 2011; 16: pii: 19935.

13. Vilibic-Cavlek T, et al. First evidence of simultaneous occurrence of West Nile virus and Usutu virus neuroinvasive disease in humans in Croatia during the 2013 outbreak. Infection 2014; 42: 689-695.

14. Ben Hassine T, et al. First detection of co-circulation of West Nile and Usutu viruses in equids in the South-west of Tunisia. Transboundary and Emerging Diseases 2014; 61: $385-389$.

15. Wasfi F, et al. West Nile virus in Tunisia, 2014: first isolation from mosquitoes. Acta Tropica 2016; 159: 106-110.

16. Tran A, et al. Environmental predictors of West Nile fever risk in Europe. International Journal of Health Geographics 2014; 13: 26.

17. Chevalier V, Tran A, Durand B. Predictive modeling of West Nile virus transmission risk in the Mediterranean Basin: how far from landing? International Journal of Environmental Research and Public Health 2013; 11: 67-90.

18. Selmi S, Boulinier T. Oases. In: Gillespie R, Clage D, eds. Encyclopedia of Islands. Berkeley: University of California Press, 2009, pp. 686-689.

19. Selmi S. Données nouvelles sur les avifaunes des oasis du Sud tunisien. Alauda 2000; 68: 201-212.

20. Selmi S, Boulinier T, Barbault R. Richness and composition of oasis bird communities: spatial issues and species-area relationships. Auk 2002; 119: 533-539.

21. Selmi S, Boulinier T. Breeding bird communities in southern Tunisian oases: the importance of traditional agricultural practices for bird diversity in a semi-natural system. Biological Conservation 2003; 110: 285-294. 
22. Hubálek Z. Mosquito-borne viruses in Europe. Parasitology Research 2008; 103: 29-43.

23. Nemeth $\mathbf{N}$, et al. Persistent West Nile virus infection in the house sparrow (Passer domesticus). Archives of Virology 2009; 154: 783-789.

24. Hammouda A, et al. Exposure of resident sparrows to West Nile virus evidenced in South Tunisia. Epidemiology and Infection 2015; 143: 3546-3549.

25. Panella NA, Young G, Komar N. Experimental infection of Eurasian collared-dove (Streptopelia decaocto) with West Nile virus. Journal of Vector Ecology 2013; 38: 210-214.

26. Pérez-Ramírez E, Llorente F, Jiménez-Clavero MÁ. Experimental infections of wild birds with West Nile virus. Viruses 2014; 6: 752-781.

27. Allison AB, et al. West Nile virus viremia in wild rock pigeons. Emerging Infectious Diseases 2004; 10: 22522255.

28. Spedicato M, et al. Experimental infection of rock pigeons (Columba livia) with three West Nile virus lineage 1 strains isolated in Italy between 2009 and 2012. Epidemiology and Infection 2016; 144: 1301-1311.

29. Halliday JE, et al. A framework for evaluating animals as sentinels for infectious disease surveillance. Journal of the Royal Society Interface 2007; 22: 973-984.

30. Baptista LF, Trail PW, Horblit HM. Family Columbidae (pigeons and doves). In: delHoyo J, Elliott A, Sargatal J, eds. Handbook of the Birds of the World. Barcelona: Lynx Edicions, 1997, vol. 4, pp. 60-245.

31. Isenmann P, et al. Birds of Tunisia. Paris: Société d'Etudes Ornithologiques de France, 2005, pp. 432.

32. Boukhriss J, Selmi S. Nidification et succès reproducteur de la Tourterelle maillée Streptopelia senegalensis dans une oasis du Sud tunisien. Alauda 2009; 77: 187-192.

33. Beck C, et al. Flaviviruses in Europe: complex circulation patterns and their consequences for the diagnosis and control of West Nile disease. International Journal of Environmental Research and Public Health 2013; 10: 6049-6083.

34. Bargaoui R, Lecollinet S, Lancelot R. Mapping the serological prevalence rate of West Nile fever in equids, Tunisia. Transboundary and Emerging Diseases 2015; 62: $55-66$.

35. Beck C, et al. A high-performance multiplex immunoassay for serodiagnosis of flavivirus-associated neurological diseases in horses. BioMed Research International 2015; 2015: 678084. doi: 10.1155/2015/678084.
36. Yeh JY, et al. A diagnostic algorithm to serologically differentiate West Nile virus from Japanese encephalitis virus infections and its validation in field surveillance of poultry and horses. Vector-Borne and Zoonotic Diseases 2012; 12: 372-379.

37. SAS Institute Inc. SAS/STAT 9.2 User's Guide. Cary: SAS Institute Inc., 2008.

38. Komar N, et al. Serologic evidence for West Nile virus infection in birds in Staten Island, New York, after an outbreak in 2000. Vector-Borne and Zoonotic Diseases 2001; 1: 191-196.

39. Godsey MS Jr., et al. West Nile virus epizootiology in the southeastern United States, 2001. Vector-Borne and Zoonotic Diseases 2005; 5: 82-89.

40. Kent R, et al. Seasonal blood-feeding behavior of Culex tarsalis (Diptera: Culicidae) in Weld county, Colorado, 2007. Journal of Medical Entomology 2009; 46: 380 390.

41. Figuerola J, et al. Size matters: West Nile Virus neutralizing antibodies in resident and migratory birds in Spain. Veterinary Microbiology 2008; 132: 39-46.

42. Černý O, Votýpka J, Svobodová M. Spatial feeding preferences of ornithophilic mosquitoes, blackflies and biting midges. Medical and Veterinary Entomology 2011; 25: 104-108.

43. Balenghien T, et al. Horse-, bird-, and human-seeking behavior and seasonal abundance of mosquitoes in a West Nile virus focus of southern France. Journal of Medical Entomology 2006; 43: 936-946.

44. Motayo BO, et al. Seasonal abundance and molecular identification of West Nile virus vectors, Culex pipens and Culex quinquefasciatus (Diptera: Culicidae) in Abeokuta, South-West, Nigeria. African Health Sciences 2016; 16: 135-140.

45. Shaman J, Goldstein E, Lipsitch M. Absolute humidity and pandemic versus epidemic influenza. American Journal of Epidemiology 2011; 173: 127-135.

46. Morin CW, Comrie AC. Regional and seasonal response of a West Nile virus vector to climate change. Proceedings of the National Academy of Sciences of the United States of America 2013; 110: 15620-15625.

47. Conte A, et al. Spatio-temporal identification of areas suitable for West Nile disease in the Mediterranean Basin and Central Europe. PLoS ONE 2015; 10: $\mathrm{e} 0146024$.

48. Gibbs SE, et al. Persistence of antibodies to West Nile virus in naturally infected Rock Pigeons (Columba livia). Clinical and Diagnostic Laboratory Immunology 2005; 12: 665-667. 